\title{
Orthopedic Research: A golden opportunity to improve patient outcomes
}

Research has been one of the core pillars of the Department of Orthopedics of the Philippine General Hospital over its now 50 years of existence. The department established one of the earliest resident's research contests in the hospital in 1983 and its graduates regularly publish in peer reviewed journals and present their results in international conferences. ${ }^{1}$ Residents are required to complete 2 original studies prior to graduation and encouraged to document their clinical cases fully for future observational studies.

Despite the apparent fascination, questions remain for a lot of trainees and clinicians. "Why do research? How does it help our patients?" Skepticism abounds as even clinically sound and well-made studies oftentimes do not lead to policy and practice changes needed to improve patient care. ${ }^{2}$ Given contrarian evidence from randomized controlled trials (RCTs), practices of most established surgeons do not change. ${ }^{3}$

Hope remains however as evidence-based practice in orthopedics is growing and here to stay. ${ }^{4}$ Surgeons who accurately examine and diagnose their patient, keep medical records, analyze the medical literature for the best treatment, and explain the available options are subconsciously practicing the scientific methods of observation, documentation, analysis, and reporting conclusions which are the basis of all scientific research. Incorporating research education not just to residency training programs but also to continuing medical education (CME) courses for surgeons may help develop the skills to comprehend new studies and incorporate them into patient care. Reassuringly for the elder surgeon, even old dogs have been shown to learn new tricks for their practice, just not as fast as the younger generation. ${ }^{5}$

The challenge now presented to Philippine medical practitioners is to develop clinical research that will translate into improved care for patients. As majority of literature dictating treatment for musculoskeletal disorders come from developed countries, case series or observational cohorts reporting local data in our setting is greatly important in guiding patient care. ${ }^{6}$ The fundamental goal is to produce high quality studies or new breakthroughs that engage discussion amongst a wide audience and lead to system changes that eventually enhance patient outcomes. ${ }^{7}$

As part of the celebration of the PGH Department of Orthopedics $50^{\text {th }}$ golden anniversary, this orthopedic issue of the ACTA MEDICA PHILIPPINA represents work from the different orthopedic subspecialities of the department and its graduates. Pioneering studies on brachial plexus injuries, computer navigated spine surgery, rotationplasty, artificial intelligence, pedagogy, and much more highlight the growth of orthopedics in the Philippines. A study on one of the newest fields in Philippine orthopedics, orthogeriatrics, exemplifies the importance of blazing a new trail.

The publication by Reyes et al. on a multidisciplinary orthogeriatric approach to the treatment of fragility hip fractures has shown improved outcomes consistent with the positive results of other fracture liaison services in Asia and worldwide. ${ }^{8,9}$ Their work has since led to the UPM-PGH Orthogeriatric Multidisciplinary Fracture Management Model and Fracture Liaison Service being adopted by PGH as a clinical pathway and has served as a model for other hospitals in the Philippines to improve their care of patients with fragility hip fractures. With the follow-through from the initial clinical study to administrative and policy changes, this example aptly illustrates the power of research to effect significant improvements in clinical outcomes and inspires all of us to continue to strive for better care for our patients.

\author{
Czar Louie Gaston, MD, FPOA \\ Department of Orthopedics \\ Philippine General Hospital \\ University of the Philippines Manila
}




\section{REFERENCES}

1. College of Medicine University of the Philippines Manila. Orthopedics [Internet]. [cited 2021 May]. Available from: https://cm.upm.edu. $\mathrm{ph} / \mathrm{p} /$ orthopedics/

2. Buchbinder R, Maher C, Harris IA. Setting the research agenda for improving health care in musculoskeletal disorders. Nat Rev Rheumatol. 2015 Oct;11(10):597-605. doi: 10.1038/nrrheum.2015.81. Epub 2015 Jun 16. PMID: 26077917.

3. Sonntag J, Landale K, Brorson S, Harris IA. Can the results of a randomized controlled trial change the treatment preferences of orthopaedic surgeons? Bone Jt Open. 2020 Sep 11;1(9):549-555. doi: 10.1302/2633-1462.19.BJO-2020-0093.R1. PMID: 33215153; PMCID: PMC7659699.

4. Griffin XL, Haddad FS. Evidence-based decision making at the core of orthopaedic practice. Bone Joint J. 2014 Aug;96-B(8):1000-1. doi: 10.1302/0301-620X.96B8.34614. PMID: 25086112.

5. Niles SE, Balazs GC, Cawley C, Bosse M, Mackenzie E, Li Y, et al. Translating research into practice: is evidence-based medicine being practiced in military-relevant orthopedic trauma? Mil Med. 2015 Apr;180(4):445-53. doi: 10.7205/MILMED-D-14-00296. PMID: 25826350 .
6. Elliott IS, Sonshine DB, Akhavan S, Slade Shantz A, Caldwell A, Slade Shantz J, et al. What factors influence the production of orthopaedic research in East Africa? A qualitative analysis of interviews. Clin Orthop Relat Res. 2015 Jun;473(6):2120-30. doi: 10.1007/s11999015-4254-5. Epub 2015 Mar 21. PMID: 25795030; PMCID: PMC4419000.

7. Tchetchik A, Grinstein A, Manes E, Shapira D, Durst R. From research to practice: Which research strategy contributes more to clinical excellence? Comparing high-volume versus high-quality biomedical research. PLoS One. 2015 Jun 24;10(6):e0129259. doi: 10.1371/ journal.pone.0129259. PMID: 26107296; PMCID: PMC4480880.

8. Chang LY, Tsai KS, Peng JK, Chen CH, Lin GT, Lin CH, et al. The development of Taiwan Fracture Liaison Service network. Osteoporos Sarcopenia. 2018 Jun;4(2):47-52. doi: 10.1016/j.afos.2018.06.001. Epub 2018 Jun 7. PMID: 30775542; PMCID: PMC6362955.

9. Barton DW, Piple AS, Smith CT, Moskal SA, Carmouche JJ. The clinical impact of fracture liaison services: A systematic review. Geriatr Orthop Surg Rehabil. 2021 Jan 11;12:2151459320979978. doi: 10.1177/2151459320979978. PMID: 33489430; PMCID PMC7809296. 